\title{
Antimicrobial usage in the chicken farming in Yaoundé, Cameroon: a cross-sectional study
}

\author{
Mélanie Gondam Kamini ${ }^{1}$, Fabrice Tatfo Keutchatang ${ }^{1,2}$, Huguette Yangoua Mafo ${ }^{1}$, Germain Kansci ${ }^{2}$ \\ and Gabriel Medoua Nama ${ }^{1 *}$
}

\begin{abstract}
Background: Antimicrobials are widely used in chicken production in Cameroon, but no quantitative data are available. A cross-sectional survey was conducted in 98 farms holding 220,262 chickens, from February to May 2015 in six areas of Yaoundé, the capital of Cameroon, to describe and quantify the use of antimicrobials.

Results: All the farms were using antimicrobials via drinking water administration. Twenty types of drugs containing antimicrobials belonging to 9 classes were recorded. $19.4 \%$ of farms used antimicrobials for therapeutic purpose, $11.2 \%$ for prophylactic purpose and $69.4 \%$ for both therapeutic and prophylactic. No disease was recorded in 36. $7 \%$ of farms during the last 3 months and $42.9 \%$ of farms were not following withdrawal periods. Fluoroquinolones, sulfonamides, tetracyclines and nitrofurans were the antimicrobials commonly used by most farms (57.1, 53.1, 46.9 and $17.3 \%$ respectively), whereas sulfonamides, tetracyclines, fluoroquinolones and nitrofurans were quantitatively the most used compounds (48.2, 26.5, 16.1 and $7.6 \%$ of the total amount of antimicrobials used). The ratio of Used Daily Doses (UDD)/Defined Daily Doses (DDD) estimating correctness of dosing showed that enrofloxacin, sulfadimethoxine and trimethoprim were underdosed in most of the administrations whereas ciprofloxacin, doxycycline, erythromycin, flumequine, furaltadone, neomycin, sulfadiazine, sulfadimidin and sulfamerazine were usually overdosed.
\end{abstract}

Conclusion: High and uncontrolled usage of antimicrobials (sulfonamides, tetracyclines and fluoroquinolones) was noted in chicken farming in Yaoundé, Cameroon, as well as usage of banned substances such as nitrofurans. It is therefore necessary to implement actions that will prevent the misuse of antimicrobials.

Keywords: Antimicrobial, Antimicrobial usage, Chicken, Cameroon

\section{Background}

To increase animal production, many chemical compounds are used as veterinary drugs with the aim of treating and preventing animal diseases, as well as improving growth performance (Page and Gautier 2012). However, their misuse can lead to the presence of residues in animal products that may have harmful effects on consumers, raison why maximum residue limits for veterinary drugs were defined in edible tissues of animal origin (Crawford 1985). The use of almost all classes of

\footnotetext{
* Correspondence: gmedoua@yahoo.fr

${ }^{1}$ Centre for Food and Nutrition Research, IMPM, PO Box 6163, Yaoundé,

Cameroon

Full list of author information is available at the end of the article
}

antimicrobials available for humans has been reported in animal production (WHO 2000), and widespread usage of antimicrobials in animal farming was associated to the development of antimicrobial-resistance which potentially decrease treatment choices for infections (WHO 2000; Apata 2009). Antimicrobial usage in animal farming could select for antimicrobial-resistant bacteria that may spread to humans either through direct contact, consumption of meat or indirectly through environmental pathways (Marshall and Levy 2011). Antimicrobial-resistance is a serious threat to global health associated to a dramatic increase of multidrug-resistant bacteria (Roca et al. 2015). To limit the advent of antimicrobial resistance, the World Health Organization recommended in 2007 
the stop for intensive routine use of antimicrobials in food production animals (Collignon et al. 2009). In some developed countries such as Sweden, Denmark, United Kingdom and Netherlands, strict control of antimicrobial usage coupled with effective surveillance of microbial resistance in the population has successfully reduced the prevalence of antimicrobial resistance (Cogliani et al. 2011; Mackie 2011). In the developing countries as Cameroon, the situation is however different; antimicrobials are readily available in local drug stores without prescription and there is no program to control antimicrobial usage (Nakajima et al. 2010). Such situation is likely to lead to misuse of antimicrobial and therefore favor development of antimicrobial resistance and public health hazards. The aim of the present study was to elucidate the usage of antimicrobials in selected chicken production units in Yaoundé, Cameroon.

\section{Methods}

\section{Study design and data collection}

This was a cross-sectional survey conducted from February to May 2015 in six areas (Mendong, Mbankomo, Nkolbisson, Byem-assi, Etoug-Ebe and Nsimalen) of Yaoundé, the capital of Cameroon. A total of 98 chicken farms containing 220,262 chickens (broilers) were randomly surveyed. A structured questionnaire was used to get data on antimicrobial usage. Farm owners were asked to provide details information on various antimicrobial drugs used within the last three months, including (i) method of administration, (ii) source of prescription, (iii) reasons for use, (iv) withdrawal period. Quantitative data on each antimicrobial drug administered were collected, including (a) the commercial name of the product and (b) the amount administered; the total amount of active antimicrobial compound was calculated from these data. The Anatomical Therapeutic Chemical classification system for veterinary medicinal products (ATCvet) was used for antimicrobial drug identification (WHOCC 2002).

\section{Data analysis}

Data were entered in Excel spreadsheet and descriptive statistic was used to estimate qualitative usage of antimicrobials in poultry farms. The quantity of antimicrobial administered was converted to $\mathrm{mg}$ of active substance per $\mathrm{kg}$ of live weight. The frequency of use of the different active substances was calculated. As described by Jensen et al. (2004), the defined daily dose (DDD) defined as the determined average maintenance dose per day and per $\mathrm{kg}$ chicken of a specific drug was calculated based on the drug's instruction leaflet. For all drugs including combination preparations, the DDD values were estimated for all active substances (antimicrobial). The used daily dose (UDD), describing the amount of active substance as administered by farmers to the animals in $\mathrm{mg} / \mathrm{kg}$, was calculated by dividing the amount of antimicrobial compound administered (mg) by the number of chicken times the average weight at treatment to define a standard treated chicken (Timmerman et al. 2006). The UDD/DDD ratios were calculated as a way to assess the correctness of dosage and based on the work reported by Timmerman et al. (2006); ratios between 0.8 and 1.2 were considered as correct dosing while values less than 0.8 and greater than 1.2 were considered to be underdosing and overdosing, respectively.

\section{Results}

\section{Qualitative estimate of antimicrobial usage}

From the 98 chicken farms visited, the majority (82.6\%) were small-scale units with population size in the range of 100-2000 chickens. Antimicrobial drugs were used in all the farms; 19 (19.4\%) of the chicken farms used antimicrobials for therapeutic purpose, 11 (11.2\%) for prophylactic purpose and $68(69.4 \%)$ for both therapeutic and prophylactic. No disease was recorded in 36 (36.7 \%) of the chicken farms during the last 3 months. Seventy-four (75.5 \%) of chicken farms signalled that antimicrobials were prescribed by a veterinary doctor or a zootechnician, while $24(24.5 \%)$ practiced selfmedication. All treatments in visited farms were applied via drinking water administration and $42(42.9 \%)$ of chicken farms declared not knowing or not applying withdrawal periods. A total of 20 different drugs containing antimicrobial were used among the 98 chicken farms (Table 1), 38 (38.3\%) of the chicken farms used one drug, 28 (28.4 \%) used 2 drugs, 25 (25.9 \%) used 3 drugs and 7 (7.4\%) 4 drugs. The active ingredients (antimicrobial) of drugs could be accurately described by direct observation of the container (Table 1); 13 drugs contained one antimicrobial, 6 drugs contained two antimicrobials and one drug contained 4 antimicrobials. A total of 17 antimicrobials belonging to 9 classes were indentified (Table 2). The antimicrobials commonly used in most farms were fluoroquinolones, sulfonamides and tetracyclines.

A total of $3(15.0 \%)$ of the drugs used in the farms contained a combination of an antimicrobial consider to be bacteriostatic with another consider to be bactericidal, 7 (35.0\%) of the drugs contained one or two antimicrobials consider as bactericidal while 10 (50.0 \%) included one or two antimicrobials consider as bacteriostatic (Table 3). In the farms visited, $46.4 \%$ of applications were with drugs containing only antimicrobials considered as bactericidal, while $59.6 \%$ applications were with drugs containing antimicrobials consider as bacteriostatic.

\section{Quantitative estimates of antimicrobial usage}

Table 4 displays the average dosage applied in the farms, described as DDD and UDD. From the UDD/ 
Table 1 Antimicrobial drugs used among the 98 chicken farms surveyed in Yaoundé, Cameroon

\begin{tabular}{|c|c|}
\hline Trade name & Composition \\
\hline Amoxicol & $\begin{array}{l}\text { Amoxicillin Trihydrate } 100 \mathrm{~g} \text {; Colistin sulfate } \\
500,000,000 \text { UI; Excipient, C.S.P } 500 \mathrm{~g}\end{array}$ \\
\hline Anticox & $\begin{array}{l}\text { Sulfadimidine sodique } 80 \mathrm{~g} \text {; Diaverindine } 8 \mathrm{~g} \text {; } \\
\text { Excipient (with vitamin K3) } 100 \mathrm{~g}\end{array}$ \\
\hline Anticoc super & $\begin{array}{l}\text { Sulfadimerazine sodique } 860 \mathrm{~g} / \mathrm{kg} \text {; Diaveridine } \\
105 \mathrm{~g} / \mathrm{kg}\end{array}$ \\
\hline Ciprosol- 200 oral & Ciprofloxacin 200 mg, Excipients ad $1 \mathrm{ml}$ \\
\hline Clortadona Ts & $\begin{array}{l}\text { Erythromycin (estolate) } 25 \text { mg/g; Neomycin } \\
\text { (sulphate) } 35 \text { mg/g; Sulfadimidine (sodium) } \\
100 \mathrm{mg} / \mathrm{g} \text {; Trimethoprim } 18 \mathrm{mg} / \mathrm{g} \text {; Bromhexine } \\
\text { hydrochloride } 1.5 \mathrm{mg} / \mathrm{g} \text {. }\end{array}$ \\
\hline Coccivit & $\begin{array}{l}\text { sulfadimidine sodique } 20 \mathrm{~g} \text {; sulfadimethoxine } \\
\text { sodique } 2 \mathrm{~g} \text {; Diaveridine } 3 \mathrm{~g} \text {; nicotinamide } \\
\text { (vitamine PP) } 3 \mathrm{~g} \text {; menadione vitamine } \mathrm{K} 32 \mathrm{~g} \text {; } \\
\text { excipient q.s.p. } 100 \mathrm{~g}\end{array}$ \\
\hline Coli-4800 WS & Colistin sulfate 4,800,000 Ul; Excipients ad $1 \mathrm{~g}$ \\
\hline Coliflox & Colistin sulfate 1,200,000 IU; Enrofloxacin 100 mg \\
\hline Diazipim - 48\%S & Trimethoprim 80 mg/g; sulfadiazine 420 mg/g \\
\hline Hipradoxi ${ }^{\oplus} \mathrm{P}$ & Doxycycline (hyclate) 100 mg/g \\
\hline Flumequine 100 & Flumequine 100 mg/ml \\
\hline Flumesol-200 WS & Flumequine 200 mg; Excipients ad $1 \mathrm{~g}$ \\
\hline Furaltadone 300 & furaltadone chlorhydrate 300 mg/g \\
\hline Norfloxacin $20 \%$ oral & Norfloxacine 200 mg; Excipients up to $1 \mathrm{ml}$ \\
\hline Limoxin-400 WS & $\begin{array}{l}\text { Oxytetracycline hydrochloride } 400 \text { mg; } \\
\text { Excipients ad } 1 \mathrm{~g}\end{array}$ \\
\hline Oxyveto $50 \mathrm{~S}$ & Oxytetracycline 500 mg/g \\
\hline Tetracycline SP 324 & Tetracycline $324 \mathrm{~g} / 454 \mathrm{~g}$ \\
\hline Trisulmix & $\begin{array}{l}\text { Sulfadimethoxine } 186.8 \mathrm{mg} / \mathrm{g} \text {; trimethoprime } \\
40.0 \mathrm{mg} / \mathrm{g}\end{array}$ \\
\hline Tromexin & $\begin{array}{l}\text { Sulfadimidine } 200 \mathrm{mg} / \mathrm{g} \text {; Trimethoprim } 60 \mathrm{mg} / \mathrm{g} \text {; } \\
\text { Bromhexine } 1.3 \mathrm{mg} / \mathrm{g} \text {; Tetracycline } 110 \mathrm{mg} / \mathrm{g}\end{array}$ \\
\hline Vetacox & $\begin{array}{l}\text { Natrium Sulfadimidin } 80 \mathrm{~g} / 100 \mathrm{~g} \text {; Diaverindin } \\
8 \mathrm{~g} / 100 \mathrm{~g}\end{array}$ \\
\hline
\end{tabular}

DDD ratio, it was noted that ciprofloxacin, doxycycline, erythromycin, flumequine, furaltadone, neomycin, sulfadiazine, sulfadimidin and sulfamerazine were usually overdosed, while enrofloxacin, sulfadimethoxine and trimethoprim were underdosed. The other compounds (amoxicilin, colistin, norfloxacine, oxytetracycline, pyrimethamine and tetracycline) were usually dosed within the range of correct dosing (UDD/DDD $=0.8-1.2)$. With $48 \%$ of the total use, sulfadimidin was the most used antimicrobial followed by oxytetracycline $(21 \%)$, norfloxacine (12\%) and furaltadone (8 \%) (Table 4). In reference to the total use, the classes of antimicrobial most used were sulfonamides (48.2\%), tetracyclines $(26.5 \%)$, fluoroquinolones $(16.1 \%)$ and nitrofurans $(7.6 \%)$.
Table 2 Type of antimicrobials used in the 98 chicken farms surveyed in Yaoundé, Cameroon

\begin{tabular}{|c|c|c|c|}
\hline Class of antimicrobial & $\begin{array}{l}\text { Name of } \\
\text { antimicrobial }\end{array}$ & $\begin{array}{l}\text { Number (\%) } \\
\text { of drugs } \\
\text { administered } \\
\text { containing the } \\
\text { antimicrobial }\end{array}$ & $\begin{array}{l}\text { Number (\%) } \\
\text { of farms } \\
\text { using the } \\
\text { antimicrobial }\end{array}$ \\
\hline$\beta$-lactam & Amoxicilin & $1(5.0)$ & $1(1.0)$ \\
\hline Aminoglycoside & Neomycin & $1(5.0)$ & $1(1.0)$ \\
\hline Diaminopyrimidines & Trimethoprim & $4(20.0)$ & $6(6.1)$ \\
\hline Fluoroquinolones & $\begin{array}{l}\text { Ciprofloxacin, } \\
\text { enrofloxacin, } \\
\text { flumequine, } \\
\text { norfloxacine }\end{array}$ & $5(25.0)$ & $56(57.1)$ \\
\hline Macrolide & Erythromycin & $1(5.0)$ & $1(1.0)$ \\
\hline Nitrofurans & Furaltadone & $1(5.0)$ & $17(17.3)$ \\
\hline Polymyxins & Colistin & $3(15.0)$ & $3(3.1)$ \\
\hline Sulfonamides & $\begin{array}{l}\text { Sulfamerazine, } \\
\text { sulfadimidine, } \\
\text { sulfadimethoxine, } \\
\text { sulfadiazine }\end{array}$ & $8(40.0)$ & $53(54.1)$ \\
\hline Tetracyclines & $\begin{array}{l}\text { Doxycycline, } \\
\text { oxytetracycline, } \\
\text { tetracycline }\end{array}$ & $5(25.0)$ & $46(46.9)$ \\
\hline
\end{tabular}

\section{Discussion}

The antimicrobial usage pattern observed in the present study showed that chicken farms administered antimicrobial medication to control diseases as all the farms investigated used one or more antimicrobial drugs for therapeutic and/or prophylactic purposes. This finding was comparable to previous studies in Africa (Turkson 2008; Nonga et al. 2009; Sirdar et al. 2012; Oluwasile et al. 2014; Bashahun and Odoch 2015) reporting high usage of antimicrobials in poultry production. As noted by Sirdar et al. (2012) in Ethiopia, the preferred method for administration of drugs in the farms visited was mass medication via drinking water. Feed was not used as route of administration; this could be because feed tend not to fully homogenize with drugs or because sick chickens will continue to drink, but will not eat (Sirdar et al. (2012).

In the present study, fluoroquinolones, sulfonamides and tetracyclines were the antimicrobials commonly used by most farms. This result agreed with previous studies in other African countries. In this regards, Nonga et al. (2009), in Tanzania, reported the use of tetracycline and sulfonamides in 90 and $85 \%$ of poultry farms respectively, Ogunleye et al. (2008), in Nigeria, reported high usage of fluoroquinolones (enrofloxacin and norfloxacin) in poultry farms. However, the above qualitative estimates of antimicrobial usage is different of the quantitative estimate of usage, where sulfonamides was by far the most used in quantitative terms, followed by tetracyclines and fluoroquinolones. A similar result was 
Table 3 Detailed description of classes of antimicrobial contained in 20 antimicrobial drugs administered by 98 chicken farms

\begin{tabular}{|c|c|c|c|c|c|c|c|}
\hline & Aminoglycoside & Sulfonamides & Fluoroquinolones & Nitrofurans & Polymyxins & Tetracyclines & $\begin{array}{l}\text { No. applications with } \\
\text { each class of } \\
\text { antimicrobial }\end{array}$ \\
\hline$\beta$-lactam & & & & & $1^{\mathrm{a}}$ & & 1 \\
\hline Diaminopyrimidines & & $4^{c}$ & & & & & 4 \\
\hline Macrolide & $1^{\mathrm{c}}$ & & & & & & 1 \\
\hline Fluoroquinolones & & & $55^{\mathrm{a}}$ & & $1^{\mathrm{a}}$ & & 56 \\
\hline Nitrofurans & & & & $17^{\mathrm{b}}$ & & & 17 \\
\hline Polymyxins & & & & & $1^{\mathrm{a}}$ & & 1 \\
\hline Sulfonamides & & $1^{\mathrm{b}}$ & & & & & 1 \\
\hline Tetracyclines & & & & & & $44^{\mathrm{b}}$ & 44 \\
\hline
\end{tabular}

obtained by a recent study in Vietnam, where it was suggested that differences between qualitative and quantitative usage could be explained by differences in the doses and concentration of active principles of the different drugs (Carrique-Mas et al. 2015).

Our results suggested that, the use of antimicrobials in chicken production in Cameroon could be problematic as a non-negligible proportion of farms investigated did not relied on veterinarians for prescription (24.5\%) and did not applied withdrawal periods (42.9\%). A similar result was reported by a recent study in the West region of Cameroon, where $49.6 \%$ of farms were not respecting withdrawal (Guetiya et al. 2016). This could be the result of factors such as lack of suitable legislation to support the responsible and prudent use of antimicrobials, lack of knowledge and lack of veterinary services (Vuuren

Table 4 Daily dosages $(\mathrm{mg} / \mathrm{kg})$ and dosing ratio of antimicrobial compounds for all treatments registered in the 98 chicken farms at Yaoundé, Cameroon

\begin{tabular}{|c|c|c|c|c|c|}
\hline ATCvet & Antibiotic & DDD & UDD & UDD/DDD & Total used $^{\mathrm{a}}[\mathrm{g}(\%)]$ \\
\hline QJ01CA04 & Amoxicilin & 9.0 & 10.0 & 1.1 & $11.5(0.12)$ \\
\hline QJ01MA02 & Ciprofloxacin & 11.4 & 50.0 & 4.4 & $25.0(0.26)$ \\
\hline QJ01XB01 & Colistin & 47.4 & 37.5 & 0.8 & $82.9(0.85)$ \\
\hline QJ01AA02 & Doxycycline & 20.0 & 38.7 & 1.9 & 478.1 (4.93) \\
\hline QJ01MA90 & Enrofloxacin & 10.0 & 5.0 & 0.5 & $8.0(0.08)$ \\
\hline QJ01FA01 & Erythromycin & 5.0 & 6.3 & 1.3 & $13.8(0.14)$ \\
\hline QJ01MB07 & Flumequine & 20.9 & 31.9 & 1.5 & 358.9 (3.70) \\
\hline QJ01XX93 & Furaltadone & 20.0 & 50.0 & 2.5 & 738.3 (7.61) \\
\hline QJ01GB05 & Neomycin & 7.0 & 8.8 & 1.3 & $19.3(0.20)$ \\
\hline QJ01MA06 & Norfloxacine & 14.5 & 11.5 & 0.8 & 1170.7 (12.06) \\
\hline QJ01AA06 & Oxytetracycline & 40.6 & 36.5 & 0.9 & 2007.0 (20.68) \\
\hline QJ01EQ10 & Sulfadiazine & 6.3 & 21.0 & 3.3 & $3.2(0.03)$ \\
\hline QJ01EQ09 & Sulfadimethoxine & 21.3 & 12.5 & 0.6 & $16.3(0.17)$ \\
\hline QJ01EQ03 & Sulfadimidin & 33.0 & 51.0 & 1.5 & 4628.3 (47.69) \\
\hline QJ01EQ17 & Sulfamerazine & 34.4 & 63.2 & 1.8 & $31.6(0.33)$ \\
\hline QJ01AA & Tetracycline & 41.6 & 37.2 & 0.9 & $88.8(0.91)$ \\
\hline QJ01EA01 & Trimethoprim & 10.8 & 6.7 & 0.6 & $22.3(0.23)$ \\
\hline
\end{tabular}

$D D D$ defined daily dose, $U D D$ used daily dose

${ }^{\text {a }}$ Percentage of the total amount of antimicrobials (in g) used 
2001). Self-medication could be associated with improper and/or illegal usage of antimicrobials while the non-application of withdrawal periods could lead to a high concentration of antimicrobial residues (above MRLs) in animal products as noted by Guetiya et al. (2016) in the West region of Cameroon. According to regulations and guidelines, antimicrobials should only be used to treat infections, respecting the dose, the length of treatment and the withdrawal (Commission Notice 2015/C 299/04). Sixty-nine percent of the farms were using antimicrobials for both therapeutic and prophylactic purposes and about $37 \%$ of the farms did not report any disease during the last 3 months; besides, several antimicrobial were underdosed. This suggested that some antimicrobials were used in the absence of clinical disease, probably to prevent infections or for growth promotion. Such usages have been linked to the development of antimicrobial resistance (Levy and Marshall 2004) as observed in chicken meat from Kenya (Odwar et al. 2014) and Cameroon (Tatsadjieu et al. 2009; Guetiya et al. 2016). In this regards, it has been reported that, the administration of antimicrobials via medicated feed or drinking water (case in the present study) lead to imprecise dosing, as animals can choose what quantity of feed or water to consume, and potentially increase selection for antimicrobial resistance (Love et al. 2011). To limit the development of antimicrobial resistance, multiple jurisdictions such European Union have banned antimicrobial use for growth promotion (European Commission 2005), but others such as the United States are still approving large number of antimicrobials for use in low doses as growth factor, arguing that restriction policies have been harmful to food animal production where they have been adopted (US Government Accountability Office 2011; Maron et al. 2013).

Most of antimicrobials recorded in the present study are considered as critically important (amoxicilin, neomycin, fluoroquinolones, erythromycin, colistin) or highly important (sulfamerazine, sulfadimidin, sulfadimethoxine, sulfadiazine, doxycycline, oxytetracycline, tetracycline) for humans by the World Health Organization (WHO 2012). In the present study, fluoroquinolones were the third most commonly used antimicrobials representing $15 \%$ of all usage in quantitative terms. This is a concern since fluoroquinolones are commonly used as a treatment for multidrug-resistant Salmonella spp. in humans (Reina et al. 1993). Besides, the use of fluoroquinolones in chicken causes the development of fluoroquinoloneresistant Campylobacter, an etiologic agent of gastroenteritis in humans (Endtz et al. 1991; Randall et al. 2003; Nelson et al. 2007). The use of banned substances such as nitrofurans, which represented $7 \%$ of all usage in quantitative terms, is also a great concern. Nitrofurans have been banned from use in food-producing animals since 1991 in the United States and 1995 in the EU because of concerns over the carcinogenicity of these compounds (FDA Vet 1991; Council Regulation 1442/95).

Results of the present study indicated that usage of antimicrobials in chicken farming is a serious threat to public health in Cameroon, and that it is necessary to take preventive actions. The safety of foods is achieved by the implementation of appropriate rules applied from primary production to retail and requires the participation of all parties involved (Codex Alimentarius 2014). Our results suggested that improper administration of antimicrobials by farmers and the lack of suitable legislation that support responsible use of antimicrobial are the key factors favoring inappropriate and uncontrolled usage of antimicrobials. This indicates that training of farmers on correct administration of antimicrobials as well as improvement of existing veterinary law would be effective strategies to restrict misuse of antimicrobials. On the other hand, it can be questioned whether the use of antimicrobials is always necessary and if alternative methods to manage infectious diseases in animal husbandry such as optimal use of existing vaccines (Potter et al. 2008) and improvement of hygiene (Boklund et al. 2004) cannot be promoted.

\section{Conclusion}

The present study revealed that, the use of antimicrobial in chicken farming in Yaoundé, Cameroon is worrisome as all the parameters for the occurrence of antimicrobial resistance and consumers hazards were met: (i) withdrawal periods before selling chickens to the public for human consumption were not followed by $43 \%$ of farmers, (ii) critically important antimicrobial such as fluoroquinolones were among the most commonly used antimicrobials, (iii) several antimicrobials were used in the absence of clinical disease to prevent infections or for growth promotion, (iv) banned substances such as nitrofurans represented $8 \%$ of all usage in quantitative terms, (v) dosage of antimicrobial in many cases was not according to the indications for the product. It is therefore necessary not only to improve existing veterinary legislations, set up a monitoring system, but also to educate farmers on alternative methods for disease management such as vaccination, environmental sanitation and disease containment, which could decrease the use of antibiotics; educate veterinary drug sellers and improve public awareness.

\section{Acknowledgements}

The present study was conducted in the framework of the IAEA technical cooperation project RAF5067. We thank all the farmers who generously gave their time and agreed to participate in this study. 


\section{Authors' contributions}

GNM drafted the research protocol, analysed the data and drafted the manuscript; MKG, FTK and HMY helped with data collection under the guidance of GK. All authors edited the manuscript and approved its final contents.

\section{Competing interests}

The authors declare that they have no competing interests.

\section{Author details}

${ }^{1}$ Centre for Food and Nutrition Research, IMPM, PO Box 6163, Yaoundé, Cameroon. ${ }^{2}$ Department of Biochemistry, Laboratory of Food Science and Metabolism, University of Yaoundé I, PO Box 812, Yaoundé, Cameroon.

Received: 20 May 2016 Accepted: 1 August 2016

Published online: 04 August 2016

\section{References}

Apata DF. Antibiotic resistance in poultry. Int J Poult Sci. 2009;8(4):404-8.

Bashahun GMD, Odoch AT (2015) Assessment of antibiotic usage in intensive poultry farms in Wakiso District, Uganda. Livest Res Rural Dev 27 (247). Available via http://www.Irrd.org//rrd27/12/bash27247.html. Accessed 16 Feb 2016

Boklund A, Alban L, Mortensen S, Houe H. Biosecurity in 116 Danish fattening swineherds: descriptive results and factor analysis. Prev Vet Med. 2004;66:49-62.

Carrique-Mas JJ, Trung NV, Hoa NT, Mai HH, Thanh TH, Campbell ال Wagenaar JA, Hardon A, Hieu TQ, Schultsz C. Antimicrobial usage in chicken production in the Mekong Delta of Vietnam. Zoonoses Public Hlth. 2015;62(1):70-8.

Codex Alimentarius (2014) Guidelines for the design and implementation of national regulatory food safety assurance programme associated with the use of veterinary drugs in food producing animals. CAC/GL 71-2009. Available via http://www.agricultura.gov.br/arq_editor/file/CRC/CAC-GL\%2071-2009.pdf. Accessed 16 Feb 2016

Cogliani C, Goossens H, Greko C. Restricting antimicrobial use in food animals: a lesson from Europe. Microbe. 2011;6:274-9.

Collignon P, Powers JH, Chiller TM, Aidara-Kane A, Aarestrup FM. World Health Organization ranking of antimicrobials according to their importance in human medicine: a critical step for developing risk management strategies for the use of antimicrobials in food production animals. Clin Infect Dis. 2009:49:132-41.

Commission Notice (2015/C 299/04) Guidelines for the prudent use of antimicrobials in veterinary medicine. Available via http://ec.europa.eu/ health/antimicrobial_resistance/docs/2015_prudent_use_guidelines_en.pdf. Accessed 16 Feb 2016

Council Regulation 1442/95. Official Journal of the European Communities (1995) L143. 26. Available via http://ec.europa.eu/health/files/mrl/regpdf/1995_06_ 26-1442_en.pdf. Accessed 16 Feb 2016

Crawford LM. The impact of residues on animal food products and human health. Rev Sci Tech Off Int Epiz. 1985;4(4):669-85.

Endtz HP, Ruijs GS, van Klingeren B, Jansen WH, vander Reyden T, Montou RP. Quinolone resistance in Campylobacter isolated from man and poultry following the introduction of fluoroquinolones in veterinary medicine. Antimicrob Chemother. 1991:27:199-208.

European Commission (2005) Ban on antibiotics as growth promoters in animal feed enters into effect, IP/05/1687. Available via http://europa.eu/rapid/ pressReleasesAction.do?reference $=\mid \mathrm{P} / 05 / 1687 \&$ format $=$ HTML\&aged $=0$ \& language $=E N \&$ guilanguage $=e n$. Accessed 16 Feb 2016

US Government Accountability Office (2011) Antibiotic resistance: agencies have made little progress addressing antibiotic use in animals. Available via http://www.gao.gov/assets/330/323090.pdf. Accessed 16 Feb 2016

Guetiya WRE, Zambou NF, Anyangwe FF, Njimou JR, Coman MM, Verdenelli MC Cecchini C, Silvi S, Orpianesi C, Cresci A, Colizzi V. Abusive use of antibiotics in poultry farming in Cameroon and the public health implications. Bri Poultry Sci. 2016. doi:10.1080/00071668.2016.1180668.

Jensen VF, Jacobsen E, Bager F. Veterinary antimicrobial-usage statistics based on standardized measures of dosage. Prev Vet Med. 2004;64:201-15.

Levy SB, Marshall B. Antibacterial resistance worldwide: causes, challenges and responses. Nat Med. 2004;10:S122-9.
Love DC, Davis MF, Bassett A, Gunther A, Nachman KE. Dose imprecision and resistance: free-choice medicated feeds in industrial food animal production in the United States. Environ Health Persp. 2011;119:279-83.

Mackie B. Lessons from Europe on reducing antibiotic use in livestock. Brit Col Med J. 2011;53(9):487.

Maron DF, Tyler JSS, Keeve EN (2013) Restrictions on antimicrobial use in food animal production: an international regulatory and economic survey. Global Health 9(48). doi:10.1186/1744-8603-9-48

Marshall BM, Levy SB. Food animals and antimicrobials: impacts on human health. Clin Microbiol Rev. 2011:24(4):718-33.

Nakajima R, Takano T, Urnaa V, Khaliun N, Nakamura K. Antimicrobial use in a country with insufficient enforcement of pharmaceutical regulations: a survey of consumption and retail sales in Ulaanbaatar, Mongolia. Southern Med Review. 2010;3(1):19-23.

Nelson M, Chiller TM, Powers JH, Angulo FJ. Fluroquinolone-resistant Campylobacter species and the withdrawal of fluroquinolone from use in poultry: a public health success story. Clin Infect Dis. 2007:44:977-80.

Nonga H, Mariki M, Karimuribo E, Mdegela R. Assessment of antimicrobial usage and antimicrobial residues in broiler chickens in Morogoro Municipality, Tanzania. Pak J Nutr. 2009:8(3):203-7.

Odwar AJ, Kikuvi G, Kariuki NJ, Kariuki S. A cross-sectional study on the microbiological quality and safety of raw chicken meats sold in Nairobi, Kenya. BMC Res Notes. 2014;7:627. doi:10.1186/1756-0500-7-627.

Ogunleye AO, Oyekunle MA, Sonibare AO. Multi-drug resistant Escherichia coli isolates of poultry origin in Abeokuta, South Western Nigeria. Vet Arhiv. 2008;78(6):501-9.

Oluwasile BB, Agbaje M, Ojo OE, Dipeolu MA. Antibiotic usage pattern in selected poultry farms in Ogun state. Sok J Vet Sci. 2014;12(1):45-50.

Page SW, Gautier P. Use of antimicrobial agents in livestock. Rev Sci Tech. 2012;31:145-88.

Potter A, Gerdts V, Littel-van den Hurk S. Veterinary vaccines: alternatives to antibiotics? Anim Health Res Rev. 2008;9:187-99.

Randall LP, Ridley AM, Cooles SW, Sharma M, Sayers AR, Pumbwe L, Newell DG, Piddock LJ, Woodward MJ. Prevalence of multiple antibiotic resistance in 443 Campylobacter spp. isolated from humans and animals. J Antimicrob Chemother. 2003;52:507-10.

Reina J, Gomez J, Serra A, Borell N. Analysis of the antibiotic resistance detected in 2043 strains of Salmonella enterica subsp. enterica isolated in stool cultures of Spanish patients with acute diarrhoea (1986-1991). J Antimicrob Chemother. 1993:32(5):765-9.

Roca I, Akova M, Baquero F, Carlet J, Cavaleri M, Coenen S, Cohen J, et al. The global threat of antimicrobial resistance: science for intervention. New Microbes New Infect. 2015;6:22-9.

Sirdar MM, Picard J, Bisschop S, Gummow B (2012) A questionnaire survey of poultry layer farmers in Khartoum State, Sudan, to study their antimicrobial awareness and usage patterns. Onderstepoort J Vet Res 79(1). doi:10.4102/ojvr.v79i1.361

Tatsadjieu LN, Tanedjeu KS, Mbofung CMF. Impact de l'utilisation des antibiotiques sur la sensibilité des bactéries pathogènes de poules dans la ville de Ngaoundéré. Cam J Exp Biol. 2009;5:52-61.

Timmerman T, Dewulf J, Catry B, Feyen B, Opsomer G, de Kruif A, Maes D. Quantification and evaluation of antimicrobial drug use in group treatments for fattening pigs in Belgium. Prev Vet Med. 2006;74:251-63.

Turkson P K (2008) Use of drugs and antibiotics in poultry production in Ghana. Ghana Journal of Agric Science 41 (1). doi:10.4314/gjas.v41i1.46142. Accessed 16 Feb 2016

FDA Vet (1991) Nitrofuran approval withdrawn 6:1-2

Vuuren MV (2001) Antibiotic resistance, with special reference to poultry production. Conf OIE :135-146. Available via http://www.oie.int/doc/ged/ D2955.PDF. Accessed 16 Feb 2016

WHO (2012) Critically important antimicrobials for human medicine, 3rd Revision 2011. World Health Organization, Geneva, Switzerland. Available via http://apps.who.int/iris/bitstream/10665/77376/1/9789241504485_eng.pdf. Accessed 16 Feb 2016

WHO Collaborating Centre for Drug Statistics Methodology (2002). Guidelines for ATCvet Classification and DDD Assignment. Available via http://www.whocc. no/atcvet. Accessed 16 Feb 2016

WHO, World Health Organization (2000) WHO global principles for the containment of antimicrobial resistance in animals intended for food. Available via http://whqlibdoc.who.int/hq/2000/WHO_CDS_CSR_APH_2000.4 pdf. Accessed 16 Feb 2016 